\title{
Co-positioning design for sustainability transitions, practice theory and transitions theories: towards dialogue and collaboration
}

\section{Elif Erdoğan Öztekin* and İdil Gaziulusoy}

\author{
NODUS Sustainable Design Research Group, \\ Department of Design, \\ Aalto University, \\ Otaniementie 16, 02150 Espoo, Finland \\ Email: elif.oztekin@aalto.fi \\ Email: idil.gaziulusoy@aalto.fi \\ ${ }^{*}$ Corresponding author
}

\begin{abstract}
This paper examines the integration potential of three bodies of knowledge that theorise and strategise about sustainability transitions and societal change: design for sustainability transitions (DfST), transitions theories (TTs) and practice theory (PT). After presenting an overview of their particular conceptions of change, narratives of change and foci of interventions, we comparatively assess: i) the dynamics of societal change that they highlight; ii) the scopes of change that they target and iii) the phases of change with which they actively engage. Our findings suggest that DfST, TTs and PT undertake distinct and yet equally relevant and necessary lenses and practices to understand and steer sustainability transitions. We argue that there is a need for establishing dialogues and collaborations between these three approaches, linking their activities, processes, learnings and propositions in order to initiate the formation of an aligned sustainability transitions research.
\end{abstract}

Keywords: sustainability transitions; societal change; transdisciplinary integration; phases of change; DfST; design for sustainability transitions; practice theory; PT; transitions theories; transitions management; multi-level perspective; narratives of change; interventions; dynamics of change; design for sustainability.

Reference to this paper should be made as follows: Erdoğan Öztekin, E. and Gaziulusoy, İ. (2020) 'Co-positioning design for sustainability transitions, practice theory and transitions theories: towards dialogue and collaboration', J. Design Research, Vol. 18, Nos. 3/4, pp.196-223.

Biographical notes: Elif Erdoğan Öztekin is pursuing her doctoral studies at Aalto University, School of Art, Design and Architecture, on the topic of design for sustainability transitions. In her doctoral research, she examines design-based learning processes that contribute to sustainability transitions by looking into cases of community-led sustainable settlement initiatives across Europe. Her research interests encompass societal transformations, whole systems change, transdisciplinary and participatory methods of knowledge coproduction. She holds a Bachelor degree in Architecture, a Master degree in Architectural Design and a Master degree in Biodigital Architecture.

İdil Gaziulusoy is an Assistant Professor of Sustainable Design and leader of NODUS Sustainable Design Research Group at Aalto University, Finland. She holds a PhD in Sustainability Science (University of Auckland, New Zealand, 
2011) and a MSc in Industrial Design (Middle East Technical University, Turkey, 2003). Her broad research interest resides at the transdisciplinary domain of sustainability transformations. The topics of empirical and theoretical focus in her current research cover urban transitions to post-carbon futures, roles and agencies of design in sustainability transformations, transformative sustainability innovation in business and post-anthropocentric design in the context of multispecies justice.

\section{Introduction}

Sustainability transitions are systemic societal change processes that proceed over several decades. Transitions unfold across several interrelated systems, such as social, technological, ecological, organisational, institutional, political and economic systems (Loorbach et al., 2017). Identifying problems, solutions and transformative actions within and across these interrelated systems requires a plurality of perspectives and worldviews to be considered and integrated (Blythe et al., 2018; Geels, 2010). This plurality of perspectives results in different interpretations of how societal change manifests; correspondingly, a multiplicity of transition strategies and transformative actions compete across different sectors of societal systems (Roberts and Geels, 2019; Turnheim et al., 2015). Given that transitions are complex and that we have limited capacity to understand their dynamics fully at any given time, transitions are associated with high levels of uncertainty. In the face of climate crises and the urgency of sustainability transitions, transformative actions and interventions have to be implemented without any certainty about their outcomes and long-term consequences (König, 2018; Mitchell et al., 2015).

As sustainability transitions are real-life phenomena that cross-cut several systemic and sectoral domains, multiple bodies of literature study and theorise about transitions, each with its own framings of system elements, processes and mechanisms of change, and different implications for practice. This holds potential for developing complementary understandings, interpretations and formulations of societal change. For instance, while exploring mobility transitions, a design approach would conduct collaborative envisioning and solution-seeking, as well as hands-on prototyping and piloting of alternative systems, services and technologies (Ceschin, 2014; Irwin, 2019). Designing and making mobility transitions require shifting between multiple perspectives and knowledge domains - tackling, on the one hand, the selection dynamics leading mobility practices (such as user preferences, needs, routines and behaviours) (Cass et al., 2018) and, on the other hand, the system elements and dynamics of mobility services (settled infrastructures, markets and industries, as well as applied policies and incentives) (Geels, 2019). Design operates at the intersection of (i) everyday practices that majorly follow the horizontal circulation of ideas, values and choices, and (ii) the infrastructures, systems and services that steer everyday practices with (iii) a strategic outlook on the multiple alternative organisational arrangements of these. In other words, designing transitions requires bridging practice and system perspectives in the pursuit of delivering strategic decisions that can enable sustainability transitions.

Building crossovers and establishing co-learning between different paradigms of change can radically improve our understandings of sustainability transitions (Geels, 2010; Luederitz et al., 2017; Meadows, 1999). This paper makes an attempt to identify 
some possibilities for the interpenetration of key bodies of knowledge dealing with sustainability transitions: design for sustainability transitions (DfST), transition theories (TTs) and social practice theory (PT). TTs and PT are commonly grounded in science, technology and society studies (STS), derived from a shared interest in the sociotechnical assemblages and innovation processes that lead wide-scale societal processes (Markard et al., 2012). DfST, on the other hand, has integrations from multiple theoretical and conceptual backgrounds, but it might be interpreted as being majorly built with integrations from TTs and system innovation perspectives (Gaziulusoy and Erdoğan Öztekin, 2019). In short, PT, TTs and DfST have multiple crossovers and overlaps. Nevertheless, in practice, these diverse knowledge domains continue to develop internally after their initial formation and establishment, and the potential for crossdisciplinary learning remains underfulfilled. Now that these approaches have gained a certain level of maturity (although to varying extents), we believe it is time to benefit from their diverse expertises, and theoretical and empirical knowledge bases in order to enrich our collective understandings of societal change processes and sustainability transitions.

We start by presenting a high-level overview of DfST, TTs and PT, focusing on their conceptions of societal change, narratives of change and foci of interventions. Next, we continue by examining the convergences and divergences of DfST, TTs and PT with regard to the dynamics of the societal change they frame and study, the kind of change that they primarily target and the phases of change to which they actively contribute. Based on this analysis, we propose a conceptual framework that co-positions these bodies of knowledge with reference to each other. Finally, in Section 4, we delineate some implications for building dialogue, continuity and collaboration between these bodies of knowledge and the real-life practices associated with them.

\section{Methodology}

While presenting, analysing and synthesising DfST, TTs and PT, this paper pursues a hybrid approach that adopts methodologies and objectives from overviews and critical reviews. By definition, an overview aims to provide a general description of a topic area by outlining its key characteristics and concepts, whereas a critical review aims to deliver analytical reflections and propose conceptual innovations in a topic area, and might further suggest a hypothesis or framework as part of its results (Grant and Booth, 2009). In this paper, we first present symmetric overviews of DfST, TTs and PT, while later we comparatively evaluate their weaknesses and strengths, and formulate implications for their future dialogue, continuity and collaboration.

DfST, TTs and PT propose different perspectives and practices to expedite and steer sustainability transitions. First, in order to overcome the challenge of proportionately analysing and presenting these three bodies of knowledge, which have quite unproportionate histories and depths of conceptual work and practice, we used the following themes and sub-questions to unpack DfST, TTs and PT approaches:

1 the conceptions of societal change (how do each of these knowledge bodies frame and understand systemic change?)

2 the narratives of societal change (how do each of these knowledge bodies frame and understand processes and flows of change?) 
3 the foci of interventions (what actions and activities do each of these knowledge bodies propose in order to achieve change?) (see Table 1).

While doing that, we looked into the primary studies and literature that have been foundational or contributory to the establishment and development of these approaches. Second, in order to overcome the pitfall of over-generalising these bodies of knowledge and neglecting their internal variations, we looked into the latest reviews that scrutinise in-depth emerging internal nuances and furthermore reflect the latest theoretical and conceptual advances in these strands of research. Third, we looked into previous works that explore the intersections between these approaches and assess the potential for their integration.

Table 1 Overview themes and related research questions

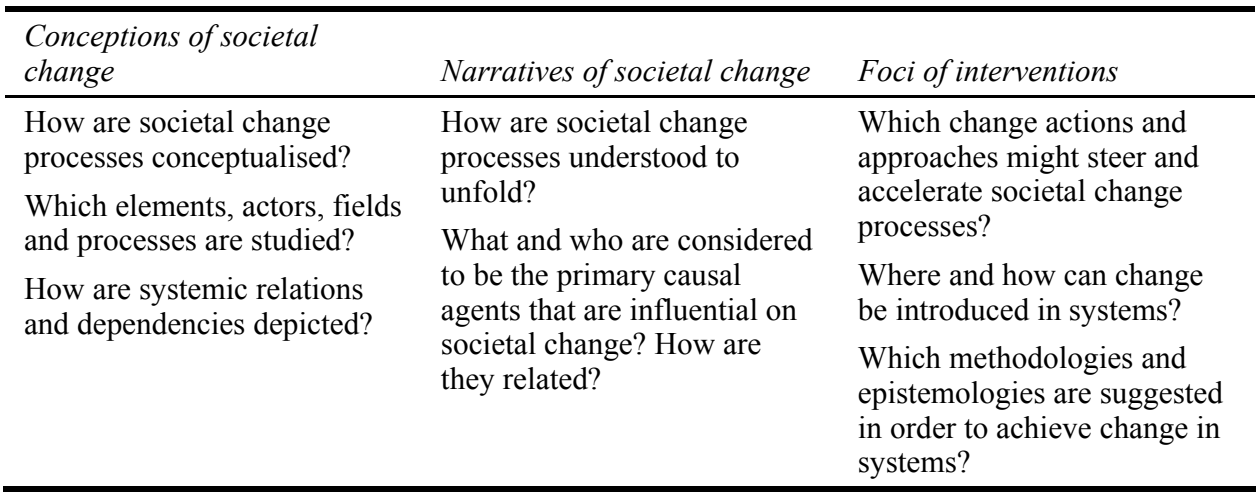

\section{Overview}

\subsection{Design for sustainability transitions}

\subsubsection{Conceptions of societal change and sustainability transitions}

Design undertakes a solution-oriented and hands-on research into sustainability transitions. DfST reconsiders the scopes, complexities and impacts of design actions and processes in the context of sustainability transitions. It emphasises the longitudinal and iterative nature of transitions and the need for designing continuities of change (Irwin, 2015). Sustainability is a system property; sustainability transitions require dynamic networks of interventions and actions rather than silver bullet solutions (Gaziulusoy, 2010; Jones, 2014; Gaziulusoy and Brezet, 2015; Doordan, 2013; Hyysalo et al., 2019). Aligned with this requirement, DfST looks into the relations, processes and causes that systemically generate large-scale sustainability problems; it reclaims systems and whole change processes as its domain and scope of design actions (Ceschin and Gaziulusoy, 2016, 2020; Kossoff, 2015; Charnley et al., 2011).

Technical and cultural matters, and material, social and ecological flows are entangled in systemic relations in the worlds of design (Young, 2008). These systemic wholes are inclusive of (i) technological systems, which comprise of products and services, technology systems and infrastructures; (ii) organisational systems, which comprise of individuals, non-governmental, governmental, industrial and market 
organisations; (iii) social/cultural systems, which comprise of values, beliefs and habits, as well as market cultures; (iv) institutional systems, which comprise of policies, strategies and predominant systems of economy, science and law (Gaziulusoy and Brezet, 2015); and (v) ecological systems, which comprise of human and non-human entities, and their relationships and interactions in the networks of living systems (Du Plessis, 2012; Veselova and Gaziulusoy, 2019). Furthermore, there are spiritual and emotional dimensions to design which are increasingly more addressed as an integral aspect of sustainability transitions (Doordan, 2013; Ives et al., 2020; Spangenberg et al., 2010).

Acknowledging this systemic complexity in which design is embedded, DfST utilises nested and interrelated levels to frame and distinguish different domains, scopes and complexities of design (Ceschin and Gaziulusoy, 2016, 2020). Young (2008) conceptualises three embedded levels: design in context (design at the level of products and artefacts), designing context (design at the level of systems and services) and design of context (design at the level of policy, ideology, purposes, values and norms). With references to this typology, it can be inferred that transitions cannot be succeeded solely by design in context, which may solve surfaced sustainability problems but fail to generate substantial changes. Transitions necessitate design of context, high-level sensemaking and problem-solving, in order to challenge and reframe predominant societal goals and values, and settled rationales of thinking and doing. Nevertheless, by acknowledging these embedded levels of contexts that design relates to, DfST can leverage transformative and systemic change even by applying design-in-context actions and interventions.

\subsubsection{Narratives of change}

DfST interprets both design outputs and design processes as potentially impactful in generating large-scale change. The narratives of change that look into the impacts of design outputs mostly refer to changes during and after the implementation of design decisions and actions. Design outputs - either products, product-service systems or sociotechnical system innovations - can alter needs and wants, and create changes in social practices, consumption and production patterns in the long run (see Vezzoli and Manzini, 2008; Ingram et al., 2007; Lockton, 2017; Hoolohan and Browne, 2020). The narratives of change that look into the impacts of design processes, on the other hand, denote that design processes of problem-solving and sense-making generate changes already before the implementation of design decisions and actions, as well as during and after them (see Vezzoli et al., 2008; Gaziulusoy, 2010; Ceschin, 2014; Gaziulusoy and Ryan, 2017; de Koning et al., 2018; Hyysalo et al., 2019). DfST does not draw clear-cut boundaries between these narratives; it embraces both by highlighting the reciprocal formation of design outputs and processes at a societal scale.

Building on Ruttonsha's (2017) work - which conceptualises three types of design contributions to sustainability transformations: design as creative agency, design as adaptive response and design as emergent engagement - we elaborate on narratives of change that are contained in DfST. Design as creative agency results from a systematised group of actions which are often led by design experts. In this process, design actions and decisions are carefully considered for their implications for social, cultural, institutional and economic systems, and for societal consumption and production patterns (Ceschin, 2014; Vezzoli et al., 2008; Joore and Brezet, 2015). This narrative of design-led change 
implies that design outputs might have a larger impact on societal change if they are formulated within extended complexity framings and perspectives on systemic wholes.

Design as adaptive response results from everyday design actions that mostly emerge informally in use. Such design refers to mundane everyday activities that are undertaken by anyone to modify surroundings, tools and objects according to their personal needs and desires (Manzini, 2015). When accumulated, these individual or local responses affect social practices and transition trajectories (Ingram et al., 2007; Spangenberg et al., 2010). This narrative of bottom-up change implies that citizens and local stakeholders' commitment to and participation in change are crucial for sustainability transitions.

Design as emergent engagement, on the other hand, results from discursive interactions and collaborative actions that are either facilitated or spontaneously occurring in design processes. These actions form a relational capital during collaborative sense-making, purpose-seeking and problem-solving (Gaziulusoy, 2010; Hyysalo et al., 2019; Irwin, 2019; De Koning et al., 2018). This narrative of emergent change implies that even though change processes cannot be controlled, self-organisation can be nurtured and capacitated by design (Dewberry and Johnson, 2010).

\subsubsection{Foci of interventions}

From a systems thinking point of view, transitions can be and need to be leveraged from various levels, processes and scales of societal systems (Meadows, 1999). Since societal systems are symbiotically integrated, everyday life (ranging from local households and neighbourhoods to cities and regions) emerges as a potential entry point for whole systems change (Kossoff et al., 2015; Kossoff, 2019; Jalas et al., 2017). Thus, domains of DfST that relate to everyday life expand across interrelated levels of product-technology systems, product-service systems, sociotechnical systems and societal systems (Ceschin and Gaziulusoy, 2016, 2020; Joore and Brezet, 2015).

Targeting changes in the organisational, cultural and cognitive aspects of design processes, the foci of interventions addressed by DfST include (but are not limited to):

- expanding the complexity framings, scopes and objectives of design actions for change

- mobilising and aligning local responses and bottom-up reactions

- facilitating participatory and collaborative processes of thinking, acting and reflecting on sustainability problems and solutions

- developing tools, methods and procedures for making transitions

- including divergent perspectives, meanings, values, needs and expectations in the formulation of interventions.

Sustainability transitions require active participation from different knowledge and action domains (Mauser et al., 2013). It is crucial to distribute ownership of change to all the stakeholders of transitions and ensure commitment to change, both in the short term and in the long run (de Koning et al., 2018). Transitions need, on one hand, fields of interaction to facilitate the emergence of alternative thoughts and actions from the multiplicity of perspectives. On the other hand, transitions also need fields of collaboration to facilitate the alignment of multiple alternative thoughts and actions 
towards (some form of) collectively strategised futures. These needs suggest changes in the practices of design, while facilitation of discursive interaction and mutual learning between different domains of knowledge and action becomes an essential activity to transitions.

\subsection{Transitions theories}

\subsubsection{Conceptions of societal change and sustainability transitions}

TTs describe the world in nested system levels which dynamically interact with each other. For example, Geels (2002) proposes a three-level structure: landscape, regime and niche levels. Landscape level refers to overarching socio-technical trends, and sociocultural and socio-ecological phenomena, creating the context of social order. This level can be interpreted as the set of ideas, beliefs and feelings forming public opinion, upon which socio-technical systems and lifestyles are built. This level also contains large-scale and long-term trends, such as climate change and other sustainability challenges, as well as longer-term technological and regulatory trends that are unfolding. Regime level refers to the settled nexus of systems, subsystems, practices and cultures that altogether form socio-technical systems and lifestyles. Regimes are shaped by industry, policy, technology, science, culture, market structures and user preferences. Internal regime dynamics persist and recreate/reaffirm regime rules and structures unless there are disruptions from the landscape level and/or strong alternatives pressuring for change from the niche level. Niche level refers to the frontiers of innovation and research where alternative socio-technical configurations get developed, experimented with and embedded in local contexts. In earlier phases of transitions, niches develop independently and niche actors are loosely connected or not connected at all. As niche innovations accumulate, they may become competitive and start to put pressure on the regime. Although there are multiple typological patterns of how exactly regimes may change (Geels and Schot, 2007), the essential premise of this multi-level perspective is that the regime changes in dynamic response to landscape-level changes and niche-level pressures.

Similarly, Loorbach (2007) proposes a conceptualisation of system levels as macro, meso and micro levels. Macro level refers to the ideas, paradigms and worldviews that form deep socio-cognitive and socio-cultural frames of reference. As this level holds societal norms, purposes and visions of change, it delineates the orientations of transitions. Meso level refers to prevailing and institutionalised structures, cultures and practices that shape system configurations and everyday life. Micro level refers to local innovations and alternatives that are experimented, implemented and evaluated for their implications on generating local change and altering system trajectories. This level also refers to the operational end of higher-level decisions, strategies and tactics. Transitions require managing interventions and changes at all these levels dynamically (Kemp et al., 2007; Voss et al., 2006). While prevailing structures and systems need to get destabilised and broken down, alternatives need to be built up, accelerated and institutionalised (Loorbach et al., 2017).

Commonly, TTs' conception of societal change signifies hierarchies of agency and structuration at system levels (Fuenfschilling and Truffer, 2014; Fischer and Newig, 2016; Pesch, 2015; Grin et al., 2011; Geels, 2010). Structuration denotes that institutionalised rules, technologies, knowledge and worldviews tend to reproduce certain 
patterns of action and interaction, and follow stabile system trajectories across time and space (Deuten, 2003; Giddens, 1984). For instance, institutionalised beliefs, values, cultures and paradigms perform structuration on local practices as they (formally and informally) determine societal norms and codes of thinking and doing; institutionalised socio-technical regimes perform structuration while enforcing inertia and path dependency on system trajectories (Fuenfschilling and Truffer, 2014). On the other hand, if protected from structuration, lower levels hold the agency to generate innovations and alternatives that can challenge predominant structures, codes and norms, and disrupt their persistencies (Longhurst, 2015; Smith and Raven, 2012; Geels and Schot, 2007).

\subsubsection{Narratives of change}

TTs suggest that sustainability transitions can be governed through long-term process management of changes in societal systems, subsystems and their interdependent relationships (Loorbach et al., 2017; Frantzeskaki et al., 2012; Kemp et al., 2007). The policy and research approaches, tools and strategies proposed by TTs expand beyond classical (top-down) steering or conventional market-led (bottom-up) steering (Kemp et al., 2007; Roberts and Geels, 2019). Narratives of change in TTs are underpinned by complex-systems thinking and evolutionary theories in the way that multi-level interventions lead to co-evolution, emergence and adaptation in systems at large (Geels and Schot, 2007; Loorbach, 2007; Smith et al., 2005; Kemp et al., 2007; Safarzyńska et al., 2012). Although interpretations of change mechanisms might vary, enhancing systemic relations and conditions for change, and interweaving multiple change processes across levels, domains and scales emerges as the umbrella narrative of TTs.

TTs propose interventionist, action-led and evidence-based processes which target transforming incumbent socio-technical regimes that fulfil societal functions (Kemp et al., 1998; Geels and Schot, 2007). Socio-technical experimentation has become a key concept in TTs, not only because it concretises ideas, plans and strategies into change actions, enables testing and improving understandings of transitions or builds evidence for policy decisions and actions (Luederitz et al., 2017; Smith and Raven, 2012), but also because experimentation initiates change while learning and it responds to the urgencies of sustainability transitions (Caniglia et al., 2017; Weiland et al., 2017; Sengers et al., 2019; Zolfgaharian et al., 2019).

There have been multiple different interpretations of experiments in TTs which demonstrate different approaches and contributions to sustainability transitions (Sengers et al., 2019). Torrens et al. (2019) identify three lenses for experimentation in TTs and their corresponding societal change narratives: (1) one that is steered by niche experimentation and that facilitates action-led learning - the seedbed narrative; (2) one that is steered by collaborative and discursive interactions between different domains of knowledge and action, and that facilitates institutional and social learning - the battleground narrative; and (3) one that is steered by networks and that facilitates relational learning and co-emergence - the harbour narrative.

First, the seedbed narrative emphasises the agencies of novel socio-technical configurations (Torrens et al., 2019). Accordingly, experiments act as 'incubation rooms' for developing innovations into solid alternatives which can disrupt regimes (Smith and Raven, 2012; Geels and Schot, 2007). Experimentation reveals information about the lived complexities of transitions such as socio-spatial embedding processes, 
local responses, sectoral reactions or policy limitations (Geels, 2019; Caniglia et al., 2017; Forrest and Wiek, 2014). Such place-based learning enables scaling, deepening and broadening transition actions and solutions (von Wirth et al., 2019; Van den Bosch and Rotmans, 2008).

Second, the battleground narrative emphasises the agencies of understanding conflicting interests and expectations, and (if possible) aligning them in order to derive shared strategies for transitions (Torrens et al., 2019). In this narrative, socio-institutional change and emancipatory processes are addressed as necessary to steer transitions (Smith et al., 2005; Avelino and Wittmayer, 2016; Ison et al., 2015; Romina, 2014; Macintyre et al., 2018). Battleground narrative highlights the processes of conflict resolution, consensus building and negotiation of meaning to facilitate mutual understanding and trust between multiple parties while generating collaborative responsibility and commitment to change (Torrens et al., 2019; Beers et al., 2019; de Koning et al., 2018; Engels and Rogge, 2018). In this way, it is projected that battlegrounds generate alternative paradigms, as well as shared visions and scenarios, for transitions (Loorbach et al., 2017; Frantzeskaki et al., 2012).

Third, considering both seedbeds and battlegrounds as necessary and impactful for change, the harbour narrative suggests bridging dispersed transition endeavours across time and space (Torrens et al., 2019). Suggesting building networks of experimentation, action and learning, this narrative highlights the agencies of facilitating distributed, and yet connected, actions and changes at multiple locales and at multiple levels (Bos et al., 2015; Frantzeskaki et al., 2019; Loorbach et al., 2020). Network governance requires orchestrating multi-domain, multi-sectoral and multi-level interactions and reflexivities (Loorbach, 2007; Roberts and Geels, 2019; Kemp et al., 2007; Grin et al., 2011), while it aims at enhancing transdisciplinary collaborations and bilateral interactions between science, policy and society (Wittmayer and Schäpke, 2014; Geels, 2019).

TTs further address co-learning as a catalyst for transitions, bridging multiple theoretical perspectives and frameworks (Geels, 2010; Zolfgaharian et al., 2019; Macintyre et al., 2018), pathways and narratives (Turnheim et al., 2015; Torrens et al., 2019; Luederitz et al., 2017; Rosenbloom et al., 2016) and geographically and contextually dispersed transitions actions (Loorbach et al., 2020; Coenen et al., 2012).

\subsubsection{Foci of interventions}

The foci of interventions in TTs are the longitudinal processes of societal change and systemic co-evolution. TTs introduce transition arenas, transition scenarios, transition experiments and transition monitoring as interrelated activities of transition governance in order to trigger and holistically manage multi-sectoral and multi-stakeholder interactions, as well as macro-, meso-, micro-level changes (Nevens et al., 2013; Frantzeskaki et al., 2012; Jørgensen, 2012; Loorbach, 2007). Actions and interventions addressed as part of network governance and transition management can be listed as:

- managing system innovation experiments for deepening, broadening, and scaling up of working solutions (von Wirth et al., 2019; van den Bosch and Rotmans, 2008)

- learning from experiments to build systems knowledge and develop policy decisions and actions (Geels and Deuten, 2006; Luederitz et al., 2017) 
- $\quad$ facilitating discursive interactions between worldviews and perspectives for building shared understandings, altering deep structures of culture, mobilising public opinion and deliberating the directionality of change (Wals and Rodela, 2014; Macintyre et al., 2018)

- enhancing sectoral, international, and scientific integrations, and transdisciplinary collaborations (Mauser et al., 2013; Schäpke et al., 2017).

These interventions aim at enhancing systemic evolutions and capacitating societies with practices, processes and skills of self-organisation. TTs provide a big picture of how these multiple foci of interventions, as a whole, contribute to steering sustainability transitions.

\subsection{Practice theory perspective on transitions}

\subsubsection{Conceptions of societal change and sustainability transitions}

PT suggests that a practice-based understanding of transitions would enrich and even shift perceptions of how societal change might unfold (Strengers and Maller, 2015). To date, practices have been variously scrutinised for their scales (e.g., individual, communal or social practices), for their dependencies (e.g., single, bundles, fields of practices) in different disciplinary contexts (sociology, philosophy, culture, science and technology) and within numerous discourses (e.g., power and governmentality, feminism and posthumanism) (Schatzki, 2001; Hui et al., 2017). This variety in practice interpretations has raised multiple strands in PT that make it difficult to provide a general description of the theory. Nevertheless, within the scope of this paper, we provide an overview of the particular strand of PT which builds crossovers with transitions theories while focusing on large-scale societal change and sustainability transitions.

From the perspective of PT, societal change and sustainability transitions are intertwined with changes in social practices; practices reflect the lived complexities of transitions. Practices are sociomaterial assemblages (Gherardi, 2017) which comprise of organised sets of actions (Hui et al., 2017), doings, sayings, things and feelings (Reckwitz, 2004, 2017; Schatzki, 2001). Shove et al. (2012) categorise the constituents of practices in three types of elements: (1) materials and tools, (2) competences and skills and (3) meanings and images. Materials and tools range from everyday objects to large-scale urban infrastructures (Shove et al., 2007; Cass et al., 2018; Shove and Trentmann, 2019). Competences and skills refer to individual and societal capabilities for performing practices that can be framed by policies, services and regulations. Meanings and images refer to personal and societal beliefs, assumptions about a practice (Shove, 2003; Shove et al., 2012). Practices get formed when these elements get linked; they evolve and disappear when their elements get unlinked and relinked.

Practices shape and get shaped not only by their elements and their dynamics but also by their socio-technical, socio-cultural and socio-cognitive contexts (Shove, 2003). Practices are situated in wider networks of multiple practices and constituents that are variously named as nexus of practices (Hui et al., 2017), meshworks of practices and discourses (Reckwitz, 2017), fields of practices (Schatzki, 2001) and practice bundles (Shove et al., 2012). In these networks, while some practices have supportive relations, some have competitive relations with one another (Spurling and McMeekin, 2015). 
These positive synergies or negative tensions affect the emergence, persistence or disappearance of practices (Shove et al., 2012).

\subsubsection{Narratives of change}

PT suggests that societal change emanates from the horizontal circulation of practice elements that break links or form new links in these networks (Shove et al., 2012). Although recognised as a relational and flat ontology (Geels, 2010), PT does not only depict diffuse agencies. Further elaborations in networks of practices imply that there are hierarchies and power relationships between alternative and mainstream practices (Shove, 2003). Spurling and McMeekin (2015) present a framework of practice levels which consolidates the conceptions, narratives and interventions outlined by PT. They introduce three levels of units of analysis to scrutinise practice situations and formulate interventions for sustainability transitions: (1) the level of practices, (2) the level of competing practices and (3) the level of practice bundles.

Analysis at the level of practices looks into the internal dynamics and elements of practices. Interventions at the level of practices aim at recrafting internal practice dynamics and elements in such a way that social practices become less resource intensive (Spurling and McMeekin, 2015; Shove et al., 2012). Nevertheless, these local interventions with limited scopes of change fall short in facilitating substantial change for transitions if they are not supplemented by interventions at other levels.

Analysis at the level of competing practices looks into the dynamics between parallel practices which serve similar functions in different ways and which might replace one another. Interventions at this level aim at substituting less sustainable practices with their more sustainable counterparts. Substitution includes recrafting the internal dynamics of competing practices as well as reorienting user needs and wants. In other words, recrafting for substitution aims at reducing the attractiveness of one practice and increasing the attractiveness of an alternative that is more sustainable. Interventions at this level affect user preferences and create fluctuations on the demand side of transitions; nevertheless, these interventions are still limited to generate deep transformations (Spurling and McMeekin, 2015).

Analysis at the level of practice bundles looks into the wider web of relations between multiple practices. Interventions at this level aim at interlocking alternative bundles of practices. In addition to recrafting and substituting, interlocking includes accessing and reshaping the underlying generative mechanisms of practices - user motivations, reasons, needs and wants - in order to break linkages and build new linkages between practices (Spurling and McMeekin, 2015). Approaching practice change from this level might generate fundamental shifts in wholes of practices and everyday lifestyles, and extensively contribute to sustainability transitions.

\subsubsection{Foci of interventions}

Changes in practices result from sociomaterial, socio-technical, socio-cultural and sociocognitive relations, interactions and learning processes that unfold across networks of practices (Alkemeyer and Buschmann, 2017; Schatzki, 2015; Shove et al., 2012; Shove, 2003). Considering their situational complexity, it is difficult to deliver general propositions for leveraging practices and sustainability transitions since impactful entry 
points and interventions for change can only be identified in the particularity of their situations, contexts, internal and external dynamics that cultivate practices. For this reason, analysis (of practice constituents, contexts and networks) and building novel understandings of practice situations have become a core focus of intervention in PT.

The foci of interventions addressed for practice-based sustainability transitions can be counted as:

- $\quad$ analysis and interpretation of local responses, user preferences and selection environment of transitions

- $\quad$ shifting transitions understandings by taking 'practices' as the unit of analysis for societal change

- $\quad$ building an evidence basis for change, which can inform practice-oriented policymaking.

Departing from TTs, PT emphasises non-purposive and contingent processes of change in transitions (Welch and Yates, 2018). Sustainability transitions are more than a projectable phenomenon that can be governed; practices, as enacted local responses, already informally govern transitions (Strengers and Maller, 2015, p.4). Accordingly, policymaking for transitions should be attentive to practices when formulating transition strategies, regulations, interventions and actions. A context-sensitive and practiceoriented, programmatic, cumulative and reflexive policymaking approach can create substantial shifts in everyday life and steer transitions (Spurling and McMeekin, 2015; Browne et al., 2015; Shove and Trentman, 2019; Hoolohan and Browne, 2020).

\subsection{Three approaches to navigate societies through transitions}

DfST, TTs and PT commonly aim to shift existing systems, processes, routines and cultures towards sustainability or to replace them with their more sustainable alternatives. This section presents their particular highlights and foundational objectives, and summarises in a nutshell their responses to overview questions (see Table 2). DfST, TTs and PT's differing conceptions of societal change have generated different narratives of change and varied their foci of interventions. Nevertheless, these approaches commonly address social inertia, routinised everyday practices and socio-technical lock-ins as major phenomena that hinder sustainability transitions and societal change. DfST, TTs and PT propose different entry points from which to intervene and steer systems, break down the persistence of unsustainable trajectories and enable the development and breakthrough of alternatives.

DfST suggests that tangible and intangible constituents of everyday life facilitate sustainability transitions directly and indirectly, formally and informally. According to DfST, transitions are wicked problems that notably relate to the decisions and actions of design; thus, transitions can be, and shall be, addressed by systemic design interventions and collaborative design processes. Transitions are continuous and connected explorations towards 'better' alternatives. DfST suggests that these explorations can be expedited if interventions are systemically tailored, processes are dynamically managed and bottom-up participation in change is enabled. 
Table 2 DfST, TTs and PT perspectives on the overviewed themes and questions

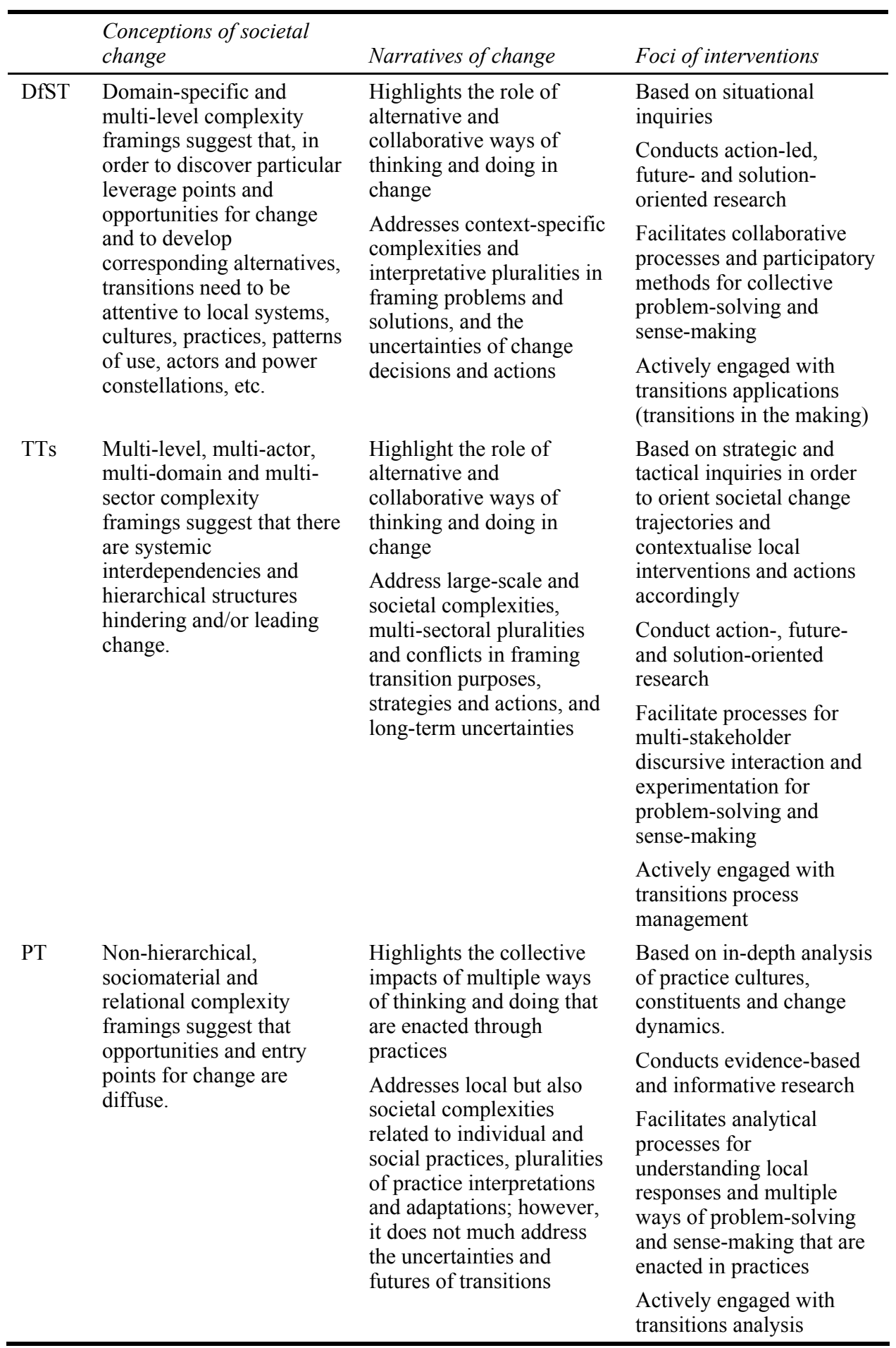


TTs, on the other hand, highlight that transitions are complex-dynamic phenomena which can be steered and accelerated by a 'right' management approach. TTs suggest that networked governance processes can enhance multi-level, multi-domain and multisectoral interactions, and facilitate participatory and collaborative processes. These processes can generate co-created transitions strategies and decisions, align multiple change actions and enable co-production of knowledge. Put shortly, in TTs, barriers to transitions are mostly recognised as problems of organisation and process management which can be overcome by collaboration and communication between isolated domains of knowledge and action.

PT highlights that transitions are informally steered by local adaptive responses that are enacted through everyday practices. The responsive relations between bottom-up practice dynamics and top-down steering need to get 'comprehensively' analysed and understood to inform transitions policies. Put shortly, in PT, barriers to transitions are mostly recognised as persisting everyday habits and routines, which can be unravelled by facilitating the evolution of practices through decision-making. Accordingly, PT proposes in-depth and context-specific analyses of practices, practice bundles and networks, and adopting a flip perspective that reflects the worlds of citizens, users or consumers.

It can be inferred that DfST, TTs and PT are not conflictful approaches, but they have developed different perspectives and expertises which are useful in overcoming different sustainability challenges. Next, we further analyse and evaluate their convergences and divergences, and in which ways these three approaches can complement one another with their strengths and assets.

\section{Convergences, divergences and complementaries between DfST, TTs and PT}

\subsection{The dynamics of societal change for sustainability}

DfST, TTs and PT all outline diverse narratives of change, but they commonly address the need for further exploring systemic relations between the individual and the whole, the micro and the macro, the context and the content, agencies and structures in order to comprehend and facilitate societal change. Waddell et al. (2015) identify two main axes of change dynamics in large-scale societal systems: vertical system interactions that can generate changes in power relationships and system structures, and horizontal interactions that can engage people, institutions and geographies in change. Taking the typology of Waddell et al. (2015) as a basis, we further elaborate on two types of change dynamics that underpin the narratives of change outlined by DfST, TTs and PT:

- co-evolution dynamics that emerge from the hierarchical interplays between highlevel steering and local responses or between different system levels

- diffusion dynamics that emerge from the circulation of ideas, worldviews, values and practices between multiple locales, sectors and actors. Accumulated meanings and values, as well as expectations and needs, lead to the emergence of similar behaviours, practices and actions across systems.

DfST, TTs and PT narratives delve into these dynamics with different highlights. TTs majorly focus on the coevolution dynamics of change and partially on diffusion dynamics. One reason for this positioning is that TTs fundamentally scrutinise mutually 
generative and disruptive relationships between hierarchical system levels and between high-level strategies and operational actions (Frantzeskaki et al., 2012; Kemp et al., 2007; Smith et al., 2005). Another reason is that, in relation to coevolution dynamics, TTs theorise the diffusion of alternative system configurations at the niche level, and alternative paradigms and worldviews at the macro level (Geels and Schot, 2007; Loorbach, 2007). There is a latent emphasis on building 'relational capital' to co-create strategies and solutions for change (Colvin et al., 2014). However, TTs perspective on diffusion dynamics is limited since selection environment and user preferences are usually referred to as abstract and homogeneous entities. Acknowledging these limitations, PT scholars propose exploring transitions through a variety of theoretical perspectives which might provide more in-depth understandings of the different dynamics, catalysers and hinderers of transitions (Shove and Walker, 2007).

PT provides an enriched look at transitions while it studies the evolution of everyday cultures and practices along with changing systems (Shove, 2003). PT mostly examines the diffusion dynamics of change as it particularly scrutinises horizontal circulations and changes of the values, meanings, competences and material innovations that lead to changes in user/consumer/citizen perspectives and practices (Zolfagharian et al., 2019; Raushmayer et al., 2015; Smith et al., 2010). Integrating systems perspectives from TTs, PT also examines co-evolution dynamics as it contextualises the emergence, persistence and disappearance of practices within the wider context of societal systems, infrastructures, cultural norms and policies (Cass et al., 2018; Shove et al., 2012; Røpke, 2009).

Aiming at delivering socially relevant alternatives which can challenge, radically disrupt and replace prevailing practices and systems, DfST requires grasping both system coevolution dynamics and diffusion dynamics. On one hand, DfST relates to the multilevel interactions and systemic relations that are theorised by TTs (Gaziulusoy and Brezet, 2015; Ceschin, 2014); on the other hand, it relates to the transformations in users/citizens responses and social practices that are theorised by PT (Spangenberg et al., 2010). Looking into hybrids of these dynamics, DfST asserts that PT and TTs narratives could be complementarily utilised to frame and assess DfSTs (Kossoff et al., 2015; Erdogan Öztekin and Gaziulusoy, 2019).

\subsection{The target scopes of change}

The scopes, scales and time frames of interventions differ in DfST, TTs and PT. Their meta-interventions target changes in the conceptions of transitions (how to understand transitions), in the processes of transitions (how to govern and steer transitions) and in transitions actions (how to decide and act for transitions). DfST, TTs and PT similarly recognise the necessity of change in each and all of the conceptions, processes and actions of transitions; however, they locate the foci of their interventions more intensely on some of them.

TTs primarily target changes in the longitudinal processes of societal decisionmaking and acting for transitions. Towards meeting this target, TTs propose process interventions from the very initial phases of transitions (e.g., transition arenas and transition scenarios) to the phases of delivering action (e.g., transition experiments) and to the phases of reflection and assessment (e.g., transition monitoring) (Loorbach, 2010; Frantzeskaki et al., 2012). The overall target is to enhance multi-level, multi-domain, multi-sectoral interactions and societal learning processes. Similarly, DfST targets 
changes in processes and suggests adopting action-led, iterative and collaborative processes. As design follows solution-oriented, non-linear and unconventional reasoning (Cross, 2006), it bases on situational inquiries in order to produce context-sensitive knowledge about transitions and it primarily targets developing actions and practices of change-making.

$\mathrm{PT}$, on the other hand, primarily targets changes in conceptions and perceptions of transitions in order to generate a practice-oriented paradigm shift in public policy. Accordingly, PT intends to redraw perceived realities and create shifts in political agendas by 'playing politics with methods' (Browne et al., 2015; Hoolohan and Browne, 2020). However, while doing that, PT limitedly addresses the shortcomings of conventional and linear science-policy interactions; thus, it limitedly reflects upon the processes of change.

\subsection{The phases of change}

Societal changes emerge from multiple interacting and coevolving change processes that are likely to coincide in the continuums of time. DfST, PT and TTs commonly recognise that societal change and sustainability transitions proceed through continuous, entangled and iterative processes of action and thinking (see Figure 1). These processes consist of multiple cycles of framing and reframing, testing and learning. According to learning scholars, cycles of thinking and action are catalysed by reflective thinking in action, on action and for action (Schön, 1983; Kolb, 1984). Similarly, transitions scholars address the reflective thinking and making processes undertaken before, during and/or after experimentation as crucial processes which enable learning and progress in sustainability transitions (Luederitz et al., 2017; Rogers et al., 2013). Design scholars take implementation of design actions and interventions as a milestone; they distinguish the types, scopes and targets of design activities that are undertaken before and after the implementation of design actions (Redström, 2008; Irwin, 2019). Designing transitions require knitting together different design activities in iterative cycles, and facilitating the continuous progress towards desirable and sustainable futures (Gaziulusoy and Brezet, 2015; Joore and Brezet, 2015).

It can be inferred that the overviewed approaches propose transitions activities that correspond to three abstract phases of change: (i) before, (ii) during and (iii) after the implementation of interventions. The before-intervention phase comprises activities such as analysing existing situations, envisioning preferred situations, formulating relevant sets of actions, hypothesising and prototyping (reflection for change). The during-intervention phase comprises activities such as contextual embedding, and implementation and modification of interventions (reflection in change). The afterintervention phase comprises activities such as follow-up observations, reflections on generated experiences and evaluation of future projections of changed situations (reflection on change).

Since TTs are concerned with the long-term process management of transitions, they deliver propositions regarding all these phases, 'zooming in and out' and 'zipping back and forth' between activities corresponding to phases before, during and after intervention (Turnheim et al., 2015; Zolfgaharian et al., 2019; Sengers et al., 2019). Nevertheless, due to its theoretical and conceptual frameworks, models and tools that mostly frame large-scale and long-term change processes, TTs can limitedly get engaged with transitions in situ and transitions in the making (Farla et al., 2012). TTs have been 
more engaged with the framings and reframings of transitions actions. As discussed by Coenen et al. (2012), TTs tend to lose sight of local change processes and fall behind in building context-sensitive understandings and actions for transitions. Consequently, although concretising strategies and scenarios into actions and experiments is fundamental to TTs, these activities can be attained to a certain degree of detailing with decision-making being done by means of TTs tools, methods and practices (see Figure 2).

Figure 1 Societal change and sustainability transitions proceed through multiple action-led learning cycles. Learnings generated by interventions inform following actions

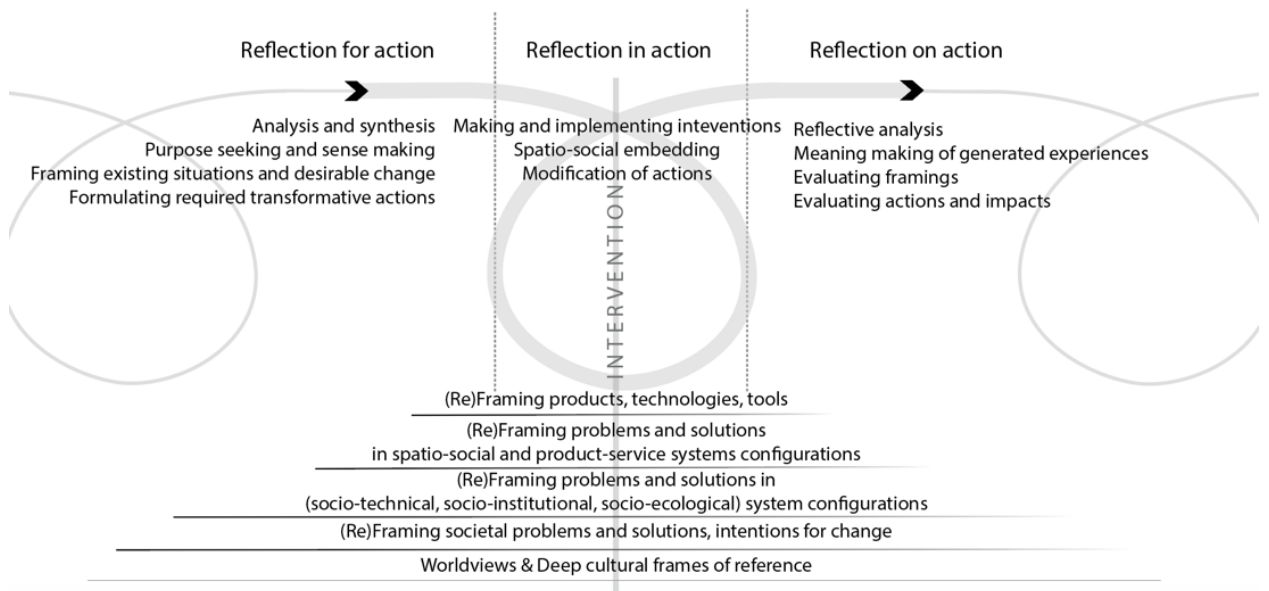

Figure 2 DfST, TTs and PT are engaged actively with varying phases of change

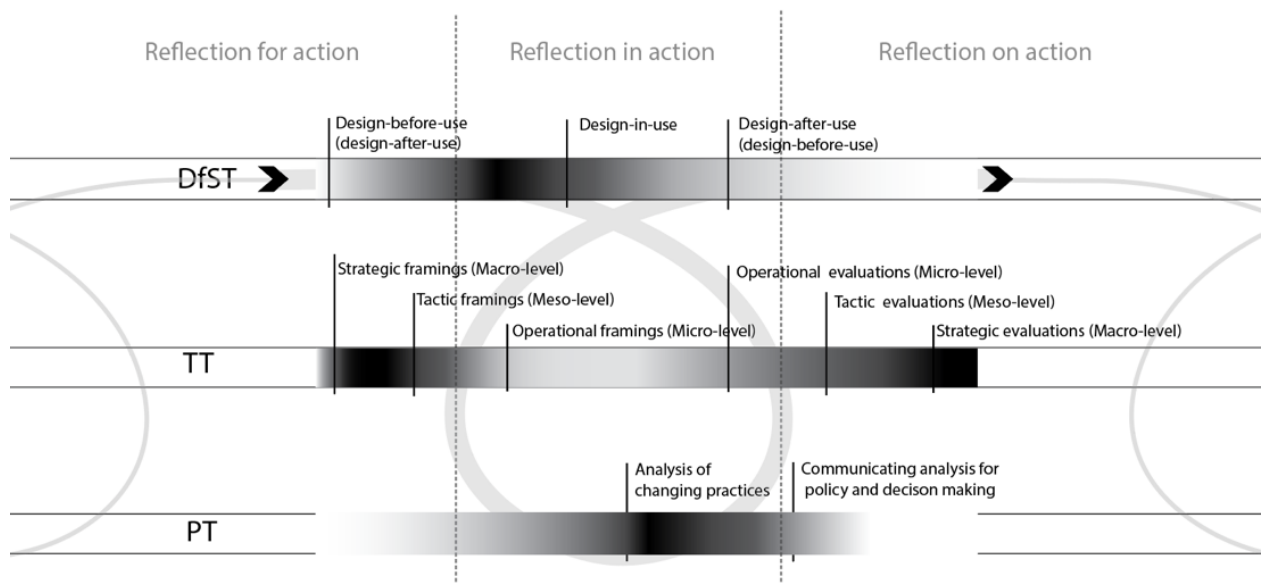

On the other hand, DfST takes a hands-on approach to transitions; it is dominantly engaged with in situ experimentation and local change processes with the aim of delivering concrete outcomes. DfST focuses on change-making and seeks to generate long-term, as well as short-term, impacts for change by pursuing collaborative design activities, processes and methods (Irwin, 2019). DfST is actively engaged with collaborative problem framing, and long-term scenario and pathway development 
processes (Hyysalo et al., 2019; Dewberry and Johnson, 2010). As demonstrated empirically (Gaziulusoy and Ryan, 2017), design and designers are engaged with strategic and tactical activities, actively co-creating transitions and future orientations. However, despite such a wide range of contributions, design is mostly associated with the contextualisation, formulation and embedding of change decisions and actions (von Wirth et al., 2019) and inevitably gets bounded in the operational corner of transitions.

Along another line, PT is engaged with the late phases of transitions, redrawing perceptions of local change processes (see Figure 2). Through detailed analyses, PT produces evidence about local responses, which can be utilised in developing public policies and strategies. Nevertheless, PT mostly generates retrospective perspectives on change. In short, DfST, TTs and PT get actively engaged in distinct phases of change; this might create epistemological incompatibilities and contradictions if they are integrated without mutual adaptations.

Evidently, sustainability transitions are long-term societal change processes and they include multiple iterative learning cycles. One might infer that reflections for, in and on interventions blend in the bigger picture; all reflections simply act as reflections in change-making.

\section{From separation of responsibilities to dialogue and collaboration in transitions research}

DfST, TTs and PT study different dynamics of change, place their foci of interventions on diverse targets and get actively engaged in distinct change phases. As discussed in the previous sections, they have built knowledge, developed strategies, practices and tools to understand and expedite different aspects of societal change (see Table 3). This comparative overview aims to lay the groundwork for discussing, discovering and exploring to what extent integrations between DfST, TTs and PT might be possible and desirable, and to what extent they might be challenging and risky. In this section, we provide a set of implications for future research which can be further developed and expanded.

Our findings indicate that there are latent separations of roles and responsibilities between DfST, TTs and PT. Because of such separations, multiple endeavours and learnings remain isolated and fail to accelerate transdisciplinary action and knowledge co-production. There is a need to bridge diverse perspectives and expertises to steer transitions from within networks of strategies, approaches and actions. Divergences of DfST, TTs and PT shall be valued for their potential to build multifaceted understandings of societal change and develop impactful actions for transitions. We propose that the relative weaknesses and strengths of DfST, TTs and PT can be reinterpreted as their complementary assets and can be taken as points of departure for their future dialogue, continuity and collaboration. In this way, a more complete understanding of transitions can be gathered which links the befores, durings and afters of change. Furthermore, in this way, the gap between understandings of transitions - transitions in theory - and practices of transitions - transitions in action (Colvin et al., 2014; Bos et al., 2013) - can begin narrowing down. 
Table 3 The strengths and weaknesses of DfST, TTs and PT in understanding, formalising and acting for transitions

\begin{tabular}{|c|c|c|c|c|c|c|c|c|}
\hline & \multicolumn{3}{|c|}{ Phases of change } & \multicolumn{3}{|c|}{ Target scopes of change } & \multicolumn{2}{|c|}{ Dynamics of change } \\
\hline & $\begin{array}{l}\text { Before } \\
\text { interventions }\end{array}$ & $\begin{array}{l}\text { During } \\
\text { interventions }\end{array}$ & $\begin{array}{l}\text { After } \\
\text { interventions }\end{array}$ & $\begin{array}{l}\text { Interventions } \\
\text { in processes }\end{array}$ & $\begin{array}{l}\text { Interventions } \\
\text { in actions } \\
\text { and practices }\end{array}$ & $\begin{array}{l}\text { Interventions } \\
\text { in } \\
\text { conceptions }\end{array}$ & $\begin{array}{l}\text { Vertical } \\
\text { coevolution } \\
\text { dynamics }\end{array}$ & $\begin{array}{l}\text { Horizontal } \\
\text { diffusion } \\
\text { dynamics }\end{array}$ \\
\hline DfST & +- & ++ & -+ & ++ (local) & ++ (local) & ++ & +- & +- \\
\hline
\end{tabular}

Weaknesses:

- Its applications are not necessarily led by in-depth analysis or theoretical propositions, but by mostly hypothetical interpretations and situational analysis of how design interventions might fluctuate the vertical and horizontal dynamics of change

- It is bounded to predefined strategies and tactics

- It does not conduct follow-up research or longitudinal analysis in order to assess the long-term, multi-level, large-scale and societal consequences of design actions

- It does not have a shared theoretical framework and thus remains hesitant to utilise context-specific learnings to improve the conceptual and theoretical understandings of transitions

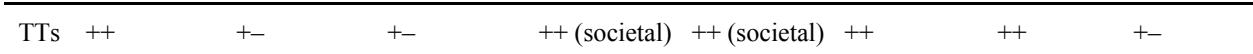

Weaknesses:

- User preferences and horizontal dynamics of change are acknowledged for their potential impacts on transitions; however, they are not proportionately researched and taken into consideration at all phases of transitions

- It loses sight of the local and context-specific opportunities for change that arise from particular systemic interdependencies and structures which are place specific

\begin{tabular}{|c|c|c|c|c|c|c|c|c|}
\hline PT & -+ & - & ++ & -+ & +- & ++ & +- & ++ \\
\hline
\end{tabular}

Weaknesses:

- $\quad$ Change actions need to be formulated after opportunities and entry points for change are rigorously analysed; this leaves no room for action-led epistemologies

- $\quad$ Research is not directly immersed in change; it rather has an 'outsider' role that produces evidence which might guide actions and decisions for change

- It deals with the aftermath of transitions actions

- It provides a retrospective look at complexities and divergences

- It takes the backseat to formulate future suggestions and prescriptive propositions in order to deal with the complexities, divergences and uncertainties of transitions

\subsection{Implications for DfST: reaching out to the of-contexts of transitions}

PT and TTs have been integrated and utilised for contextualising design actions in sustainability transitions. But without follow-up analysis, DfST integrations do not produce learning for future theoretical development; thus, the of-contexts of transitions continue to remain beyond the reach of design. First, it is necessary to establish shared DfST frameworks and networks of transitions projects framed by DfST (Gaziulusoy, 2019; Kossoff, 2015). Second, it is necessary to monitor and evaluate the systemic impacts of design interventions and practices; it shall no longer be an optional research activity. Third, learnings emerging from DfST action networks shall be collaboratively translated into generalisable propositions and fed into transition theories and discourses. Fourth, above all, DfST shall emphasise design as a culture of learning (Buchanan, 2001) 
and advocate enabling the equal influence of design in the processes of knowledge co-creation and decision-making for transitions.

\subsection{Implications for TTs: democratising collaboration and participation across phases of transitions}

On the flip side, TTs shall formulate multi-sectoral processes and transdisciplinary collaborations that open up equal opportunities for different strands of research in the co-creation of transition discourses, decisions and actions. There are multifaceted contributions of DfST and PT to societal change. Design epistemologies that convey action-led knowledge production, problem-solving and sense-making processes require further recognition in transitions (Diethelm, 2016; Cross, 2006; Buchanan, 2001). Similarly, practice perspectives require further recognition for their potential to identify and loosen use-related barriers to transitions, such as social inertia, path dependencies and lock-ins. Although TTs address user preferences as a major system constituent, it has understudied the dynamic circulation and evolution of user values, needs and expectations (Rauschmayer et al., 2015). PT and TTs collaborations might explore linking PT analyses and interpretations (reflections on change) with transitions strategies (reflections for change). When TTs build bilateral collaborations and dialogues with DfST and PT, they would, on one hand, enhance societal reflexivities and, on the other hand, get more actively engaged with place-based transitions.

\subsection{Implications for PT: epistemological turns that enable active engagement with change}

PT shall move beyond solely providing retrospective perspectives and analyses of change, and shall further explore ways to get actively engaged in change-making and practices of change-making. As $\mathrm{PT}$ delves into in-depth examination of the selection side complexities of transitions, it fails to respond to the urgencies of transitions and deliver more direct and practice-oriented impact for change. PT could explore an epistemological turn and integrate action-led methodologies in its research approach. Studies at the intersection of practices, design and sustainability (Strengers, 2011; Kuijer, 2014; Kuijer and Bakker, 2015; Jalas et al., 2017) are promising leads to such explorations because they delineate how PT lenses might be implemented in design-led change-making, and how design experiments might provide empirical bases from which to develop practicebased understandings of sustainability transitions. Further explorations and collaborations with DfST and TTs can entail methodological shifts in PT and ultimately establish more nonlinear, unconventional and dynamic practice research.

\section{Conclusions}

This paper presents an overview of three bodies of knowledge on sustainability transitions - DfST, TTs and PT - with the aim of examining their convergences, divergences and complementariness, and exploring the potential for their future dialogue and collaboration. Our analysis indicates that DfST, TTs and PT have divergences, but also foundational convergences and potential complementariness in their conceptions of societal change, narratives of change and foci of interventions. PT scholars argue for 
building thicker descriptions and practice-based understandings, developing alternative interpretations which can inform high-level policies, regulations and decisions for change (Reckwitz, 2004; Shove, 2003; Rauschmayer et al., 2015; Strengers and Maller, 2015; Shove and Trentmann, 2019). TTs scholars, on the other hand, suggest enhancing interactions between different domains of knowledge and action to enhance the coevolution and diffusion of discourses, systems and practices (Kemp et al., 2007; Loorbach, 2007). Further, they propose building knowledge and competence for transitions through local action and experimentation, which contribute to loosening the uncertainties of transitions and forming an empirical basis for high-level steering and management (Geels and Schot, 2007; Geels and Deuten, 2006). DfST scholars emphasise the potential contributions of collaborative design processes and systemic actions in large-scale societal change. Design outputs mediate multi-level system coevolution, as well as discursive and practical diffusion, while design processes facilitate mutual understanding and collaborative learning between the stakeholders of change (Vezzoli et al., 2008; Ceschin, 2014; Gaziulusoy and Ryan, 2017). Furthermore, several scholars from TTs and PT promote integrating ways of thinking and doing from design in order to deal better with the multi-faceted societal issues related to sustainability transitions (De Koning et al., 2018; Hoolohan and Browne, 2020; Bos et al., 2013).

Despite their different framings and approaches to change, DfST, TTs and PT do recognise each other's conceptions, narratives and interventions as critical and intrinsic to transitions. Nevertheless, they target different types of change with their interventions. DfST targets changes in transition actions and practices by outlining activities for change-making. TTs target changes in transitions processes by outlining management approaches for accelerating, aligning and steering complex-dynamic societal change processes. PT targets changes in the conceptions of transitions by providing perspectives from users and everyday practices and analysing their relational interdependencies with systems.

This paper proposes a conceptual framework that illustrates how DfST, TTs and PT participate and contribute to different phases of change. DfST, TTs and PT seem to undertake latent roles and responsibilities in transitions. Such divisions of roles and responsibilities provoke deeper segregation of expertises, gaps between the discourses and practices of transitions, conflicts of research interests or epistemological mismatches. However, plurality of perspectives, approaches and projects is also necessary to proceed through the complexities and uncertainties of sustainability transitions. Thus, integrative work is essential in order to build transdisciplinary dialogue, continuity and collaboration between diverse knowledges and practices; DfST, TTs and PT provide a fertile ground for such integrative explorations.

The proposed conceptual framework can be utilised as a heuristic tool for analysing and evaluating the relative weaknesses and strengths of different research approaches, and for co-positioning their participation and contribution to change with reference to each other. In this way, the proposed conceptual framework can enable establishing a basis for further transdisciplinary integrations, either for forming collaborative research projects or programs, or for linking spatially and timewise dispersed transitions endeavours. 


\section{Acknowledgements}

We would like to thank two anonymous reviewers of this paper for their useful comments. This research was supported by Nessling Foundation (Project no: 201900132).

\section{References}

Alkemeyer, T. and Buschmann, N. (2017) 'Learning in and across practices: enablement as subjectivation', in Hui, A., Schatzki, T.R. and Shove, E. (Eds.): The Nexus of Practices: Connections, Constellations and Practitioners, Routledge, New York, pp.8-23.

Avelino, F. and Wittmayer, J.M. (2016) 'Shifting power relations in sustainability transitions: a multi-actor perspective', Journal of Environmental Policy and Planning, Vol. 18, No. 5, pp.628-649.

Beers, P.J., Turner, J.A., Rijswijk, K., Williams, T., Barnard, T. and Beechener, S. (2019) 'Learning or evaluating? towards a negotiation-of-meaning approach to learning in transition governance', Technological Forecasting and Social Change, Vol. 145, pp.229-239.

Blythe, J., Silver, J., Evans, L., Armitage, D., Bennett, N.J., Moore, M-L., Morrison, T.H. and Brown, K. (2018) 'The dark side of transformation: latent risks in contemporary sustainability discourse', Antipode, Vol. 50, No. 5, pp.1206-1223.

Bos, J.J., Brown, R.R. and Farrelly, M.A. (2013) 'A design framework for creating social learning situations', Global Environmental Change, Vol. 23, No. 2, pp.398-412.

Bos, J.J., Brown, R.R. and Farrelly, M.A. (2015) 'Building networks and coalitions to promote transformational change: insights from an Australian urban water planning case study', Environmental Innovation and Societal Transitions, Vol. 15, pp.11-25.

Browne, A., Medd, W., Anderson, B. and Pullinger, M. (2015) 'Method as intervention: intervening in practice through quantitative and mixed methodologies', in Strengers, Y. and Maller, C. (Eds.): Social Practices, Intervention and Sustainability: Beyond Behaviour Change, Routledge, Oxfordshire, New York, pp.179-195.

Buchanan, R. (2001) 'Design research and the new learning', Design Issues, Vol. 17, No. 4, pp.3-23.

Caniglia, G., Schäpke, N., Lang, D.J., Abson, D.J., Luederitz, C., Wiek, A., Laubichler, M.D., Gralla, F. and von Wehrden, H. (2017) 'Experiments and evidence in sustainability science: a typology', Journal of Cleaner Production, Vol. 169, pp.39-47.

Cass, N., Schwanen, T. and Shove, E. (2018) 'Infrastructures, intersections and societal transformations', Technological Forecasting and Social Change, Vol. 137, pp.160-167.

Ceschin, F. (2014) 'How the design of socio-technical experiments can enable radical changes for sustainability', International Journal of Design, Vol. 8, No. 3, pp.1-21.

Ceschin, F. and Gaziulusoy, İ. (2016) 'Evolution of design for sustainability: from product design to design for system innovations and transitions', Design Studies, Vol. 47, pp.118-163.

Ceschin, F. and Gaziulusoy, İ. (2020) Design for Sustainability: A Multi-Level Framework from Products to Socio-Technical Systems, Routledge, London.

Charnley, F., Lemon, M. and Evans, S. (2011) 'Exploring the process of whole system design', Design Studies, Vol. 32, No. 2, pp.156-179.

Coenen, L., Benneworth, P. and Truffer, B. (2012) 'Toward a spatial perspective on sustainability transitions', Research Policy, Vol. 41, No. 6, pp.968-979.

Colvin, J., Blackmore, C., Chimbuya, S., Collins, K., Dent, M., Goss, J., Ison, R., Roggero, P.P. and Seddaiu, G. (2014) 'In search of systemic innovation for sustainable development: a design praxis emerging from a decade of social learning inquiry', Research Policy, Vol. 43, No. 4, pp.760-771. 
Cross, N. (2006) Designerly Ways of Knowing, New York: Springer.

De Koning, J., Puerari, E., Mulder, I. and Loorbach, D. (2018) 'Design-enabled participatory city making', Proceedings of 2018 IEEE International Conference on Engineering, Technology and Innovation (ICE/ITMC). 18-20 June, Stuttgart, pp.1-9, doi: 10.1109/ICE.2018.8436356.

Deuten, J.J. (2003) Cosmopolitanising Technologies: A Study of Four Emerging Regimes, $\mathrm{PhD}$ Thesis, University of Twente.

Dewberry, E. and Johnson, J. (2010) 'Design interventions, prediction and science in the sustainable transition of large, complex system', The 2nd International Conference on Design Engineering and Science ICDES, 17-19 November, Tokyo, http://oro.open.ac.uk/26351/ (Accessed 10 November, 2020).

Diethelm, J. (2016) 'De-colonizing design thinking', She-Ji The Journal of Design, Economics, and Innovation, Vol. 2, No. 2, pp.166-172.

Doordan, D.P. (2013) 'Developing theories for sustainable design', in Walker, S. and Giard, J. (Eds.): The Handbook of Design for Sustainability, Bloomsbury, London: New York, pp.57-72.

Du Plessis, C. (2012) 'Towards a regenerative paradigm for the built environment', Building Research and Information, Vol. 40, No. 1, pp.7-22.

Engels, F. and Rogge, J.C. (2018) 'Tensions and trade-offs in real-world laboratories - the participants' perspective', GAIA, Vol. 27, Sup.1, pp.28-31.

Erdogan Öztekin, E. and Gaziulusoy, A.İ. (2019) 'Designing transitions bottom-up: the agency of design in formation and proliferation of niche practices', The Design Journal, Vol. 22, sup.1, pp.1659-1674.

Farla, J., Markard, J., Raven, R. and Coenen, L. (2012) 'Sustainability transitions in the making: a closer look at actors, strategies and resources', Technological Forecasting and Social Change, Vol. 79, No. 6, pp.991-998.

Fischer, L.B. and Newig, J. (2016) 'Importance of actors and agency in sustainability transitions: a systematic exploration of the literature', Sustainability, Vol. 8, No. 5, p.476, doi: 10.3390/ su8050476.

Forrest, N. and Wiek, A. (2014) 'Learning from success - toward evidence-informed sustainability transitions in communities', Environmental Innovation and Societal Transitions, Vol. 12, pp.66-88.

Frantzeskaki, N., Buchel, S., Spork, C., Ludwig, K. and Kok, M.T.J. (2019) 'The multiple roles of ICLEI: intermediating to innovate urban biodiversity governance', Ecological Economics, Vol. 164: 106350, doi: 10.1016/j. ecolecon.2019.06.005.

Frantzeskaki, N., Loorbach, D. and Meadowcroft, J. (2012) 'Governing societal transitions to sustainability', International Journal of Sustainable Development, Vol. 15, Nos. 1-2, pp.19-36.

Fuenfschilling, L. and Truffer, B. (2014) 'The structuration of socio-technical regimes-conceptual foundations from institutional theory', Research Policy, Vol. 43, No. 4, pp.772-791.

Gaziulusoy, İ. And Erdoğan Öztekin, E. (2019) 'Design for sustainability transitions: origins, attitudes and future directions', Sustainability, Vol. 11, No. 13: 3601, doi: 10.3390/ su11133601.

Gaziulusoy, A.İ. (2010) System Innovation for Sustainability: A Scenario Method and a Workshop Process for Product Development Teams, PhD thesis, University of Auckland.

Gaziulusoy, A.İ. (2019) 'Postcards from 'the edge': toward futures of design for sustainability transitions', Cuadernos Del Centro De Estudios En Diseño y Comunicación, Vol. 73, July, pp.67-84.

Gaziulusoy, A.İ. and Brezet, H. (2015) 'Design for system innovations and transitions: a conceptual framework integrating insights from sustainability science and theories of system innovations and transitions', Journal of Cleaner Production, Vol. 108, pp.558-568. 
Gaziulusoy, A.İ. and Ryan, C. (2017) 'Roles of design in sustainability transitions projects: a case study of visions and pathways 2040 project from Australia', Journal of Cleaner Production, Vol. 162, pp.1297-1307.

Geels, F.W. (2002) 'Technological transitions as evolutionary reconfiguration processes: a multilevel perspective and a case-study', Research Policy, Vol. 31, Nos. 8-9, pp.1257-1274.

Geels, F.W. (2010) 'Ontologies, socio-technical transitions (to sustainability) and the multi-level perspective', Research Policy, Vol. 39, No. 4, pp.495-510.

Geels, F.W. (2019) 'Socio-technical transitions to sustainability: a review of criticisms and elaborations of the multi-level perspective', Current Opinion in Environmental Sustainability, Vol. 39, pp.187-201.

Geels, F.W. and Deuten, J.J. (2006) 'Aggregation activities: local and global dynamics in technological development - A socio-cognitive perspective on knowledge flows and lessons from reinforced concrete', Science and Public Policy, Vol. 33, No. 4, pp.265-275.

Geels, F.W. and Schot, J. (2007) 'Typology of sociotechnical transition pathways', Research Policy, Vol. 36, No. 3, pp.399-417.

Gherardi, S. (2017) 'Sociomateriality in posthuman practice theory', in Hui, A., Schatzki, T.R. and Shove, E. (Eds.): The Nexus of Practices: Connections, Constellations and Practitioners, Routledge, New York.

Giddens, A. (1984) The Constitution of Society, Polity Press, Cambridge, UK.

Grant, M.J. and Booth, A. (2009) 'A typology of reviews: an analysis of 14 review types and associated methodologies', Health Information and Libraries Journal, Vol. 26, No. 2, pp.91-108.

Grin, J., Rotmans, J. and Schot, J. (2011) 'On patterns and agency in transition dynamics: some key insights from the KSI programme', Environmental Innovation and Societal Transitions, Vol. 1, No. 1, pp.76-81.

Hoolohan, C. and Browne, A. (2020) 'Design thinking for practice-based intervention: co-producing the change points toolkit to unlock (un) sustainable practices', Design Studies, Vol. 67, pp.102-132.

Hui, A., Schatzki, T.R. and Shove, E. (Eds.) (2017) The Nexus of Practices: Connections, Constellations and Practitioners, Routledge.

Hyysalo, S., Marttila, T., Perikangas, S. and Auvinen, K. (2019) 'Codesign for transitions governance: a mid-range pathway creation toolset for accelerating sociotechnical change', Design Studies, Vol. 63, pp.181-203.

Ingram, J., Shove, E. and Watson, M. (2007) 'Products and practices: selected concepts from science and technology studies and from social theories of consumption and practice', Design Issues, Vol. 23, No. 2, pp.3-16.

Irwin, T. (2015) 'Transition design: a proposal for a new area of design practice, study, and research', Design and Culture, Vol. 7, No. 2, pp.229-246.

Irwin, T. (2019) 'The emerging transition design approach', Cuadernos Del Centro De Estudios En Diseño y Comunicación, Vol. 87, pp.27-54.

Ison, R.L., Collins, K.B. and Wallis, P.J. (2015) 'Institutionalising social learning: towards systemic and adaptive governance', Environmental Science and Policy, Vol. 53, pp.103-115.

Ives, C.D., Freeth, R. and Fischer, J. (2020) 'Inside-out sustainability: the neglect of inner worlds', Ambio, Vol. 49, No. 1, pp.208-217.

Jalas, M., Hyysalo, S., Heiskanen, E., Lovio, R., Nissinen, A., Mattinen, M., Rinkinen, J., Juntunen, J.K., Tainio, P. and Nissilä, H. (2017) 'Everyday experimentation in energy transition: a practice-theoretical view', Journal of Cleaner Production, Vol. 169, pp.77-84.

Jones, P.H. (2014) 'Systemic design principles for complex social systems', in Metcalf, G.S. (Ed.): Social Systems and Design, Springer, Japan, pp.91-128. 
Joore, P. and Brezet, H. (2015) 'A multilevel design model: the mutual relationship between product-service system development and societal change processes', Journal of Cleaner Production, Vol. 97, pp.92-105.

Jørgensen, U. (2012) 'Mapping and navigating transitions - the multi-level perspective compared with arenas of development', Research Policy, Vol. 41, No. 6, pp.996-1010.

Kemp, R., Loorbach, D. and Rotmans, J. (2007) 'Transition management as a model for managing processes of co-evolution towards sustainable development', The International Journal of Sustainable Development and World Ecology, Vol. 14, No. 1, pp.78-91.

Kemp, R., Schot, J. and Hoogma, R. (1998) 'Regime shifts to sustainability through processes of niche formation: the approach of strategic niche management', Technology Analysis and Strategic Management, Vol. 10, No. 2, pp.175-198.

Kolb, D. (1984) Experiential Learning: Experience as the Source of Learning and Development, Prentice-Hall, Englewood Cliffs, NJ.

König, A. (2018) 'Sustainability science as a transformative social learning process', in König, A. and Ravetz, J.R. (Eds.): Sustainability Science: Key Issues, Routledge, pp.3-28.

Kossoff, G. (2015) 'Holism and the reconstitution of everyday life: a framework for transition to a sustainable society', Design Philosophy Papers, Vol. 13, No. 1, pp.25-38.

Kossoff, G. (2019) 'Cosmopolitan localism: the planetary networking of everyday life in place introduction: cosmopolitan localism as a transition design strategy', Cuadernos Del Centro De Estudios En Diseño y Comunicación, Vol. 73, July, pp.51-66.

Kossoff, G., Tonkinwise, C. and Irwin, T. (2015) 'Transition design: the importance of everyday life and lifestyles as a leverage point for sustainability transitions', The 6th International Sustainability Transitions Conference, August, University of Sussex, UK.

Kuijer, L. (2014) Implications of Social Practice Theory for Sustainable Design, PhD Thesis. Technische Universiteit Delft.

Kuijer, L. and Bakker, C. (2015) 'Of chalk and cheese: behaviour change and practice theory in sustainable design', International Journal of Sustainable Engineering, Vol. 8, No. 3, pp.219-230.

Lockton, D. (2017) 'Design with intent and the field of design for sustainable behaviour', in Keyson, D., Guerra-Santin, O. and Lockton, D. (Eds.): Living Labs. Springer, Cham, pp.75-88.

Longhurst, N. (2015) 'Towards an 'alternative' geography of innovation: alternative milieu, socio-cognitive protection and sustainability experimentation', Environmental Innovation and Societal Transitions, Vol. 17, pp.183-198.

Loorbach, D. (2007) Transition Management: New Mode of Governance for Sustainable Development, $\mathrm{PhD}$ Thesis, Erasmus Universiteit Rotterdam.

Loorbach, D. (2010) 'Transition management for sustainable development', Governance: An International Journal of Policy, Administration and Institutions, Vol. 23, No. 1, pp.161-183.

Loorbach, D., Frantzeskaki, N. and Avelino, F. (2017) 'Sustainability transitions research: transforming science and practice for societal change', Annual Review of Environment and Resources, Vol. 42, pp.599-626.

Loorbach, D., Wittmayer, J., Avelino, F., von Wirth, T. and Frantzeskaki, N. (2020) 'Transformative innovation and translocal diffusion', Environmental Innovation and Societal Transitions, Vol. 35, pp.251-260.

Luederitz, C., Abson, D.J., Audet, R. and Lang, D.J. (2017) 'Many pathways toward sustainability: not conflict but co-learning between transition narratives', Sustainability Science, Vol. 12, No. 3, pp.393-407.

Luederitz, C., Schäpke, N., Wiek, A., Lang, D.J., Bergmann, M., Bos, J.J., Burch, S., Davies, A., Evans, J., König, A., Farrelly, M.A., Forrest, N., Frantzeskaki, N., Gibson, R.B., Kay, B., Loorbach, D., McCormick, K., Parodi, O., Rauschmayer, F. and Westley, F.R. (2017) 'Learning through evaluation - A tentative evaluative scheme for sustainability transition experiments', Journal of Cleaner Production, Vol. 169, pp.61-76. 
Macintyre, T., Lotz-Sisitka, H., Wals, A., Vogel, C. and Tassone, V. (2018) 'Towards transformative social learning on the path to 1.5 degrees', Current Opinion in Environmental Sustainability, Vol. 31, pp.80-87.

Manzini, E. (2015) Design, When Everybody Designs: An Introduction to Design for Social Innovation, MIT Press, Cambridge.

Markard, J., Raven, R. and Truffer, B. (2012) 'Sustainability transitions: an emerging field of research and its prospects', Research Policy, Vol. 41, No. 6, pp.955-967.

Mauser, W., Klepper, G., Rice, M., Schmalzbauer, B.S., Hackmann, H., Leemans, R. and Moore, H. (2013) 'Transdisciplinary global change research: the co-creation of knowledge for sustainability', Current Opinion in Environmental Sustainability, Vol. 5, pp.420-431.

Meadows, D. (1999) Leverage Points: Places to Intervene in a System, The Sustainability Institute, Hartland.

Mitchell, C., Cordell, D. and Fam, D. (2015) 'Beginning at the end: the outcome spaces framework to guide purposive transdisciplinary research', Futures, Vol. 65, pp.86-96.

Nevens, F., Frantzeskaki, N., Gorissen, L. and Loorbach, D. (2013) 'Urban transition labs: co-creating transformative action for sustainable cities', Journal of Cleaner Production, Vol. 50, pp.111-122.

Pesch, U. (2015) 'Tracing discursive space: agency and change in sustainability transitions', Technological Forecasting and Social Change, Vol. 90, pp.379-388.

Rauschmayer, F., Bauler, T. and Schäpke, N. (2015) 'Towards a thick understanding of sustainability transitions - linking transition management, capabilities and social practices', Ecological Economics, Vol. 109, pp.211-221.

Reckwitz, A. (2004) 'Toward a theory of social practices: a development in culturalist theorizing', Practicing History: New Directions in Historical Writing after the Linguistic Turn, Vol. 5, No. 2, pp.245-263.

Reckwitz, A. (2017) 'Practices and their affects', in Hui, A., Schatzki, T.R. and Shove, E. (Eds.): The Nexus of Practices: Connections, Constellations and Practitioners, Routledge, New York, pp.114-125.

Redström, J. (2008) 'RE: definitions of use', Design Studies, Vol. 29, No. 4, pp.410-423.

Roberts, C. and Geels, F.W. (2019) 'Conditions and intervention strategies for the deliberate acceleration of socio-technical transitions: lessons from a comparative multi-level analysis of two historical case studies in Dutch and Danish heating', Technology Analysis and Strategic Management, Vol. 31, No. 9, pp.1081-1103.

Rogers, K.H., Luton, R., Biggs, H., Biggs, R.O., Blignaut, S., Choles, A.G. and Carolyn, G. (2013) 'Fostering complexity thinking in action research for change in social-ecological systems', Ecology and Society, Vol. 18, No. 2, p.31, doi: 10.5751/ES-05330-180231.

Romina, R. (2014) 'Social learning, natural resource management, and participatory activities: a reflection on construct development and testing', NJAS - Wageningen Journal of Life Sciences, Vol. 69, pp.15-22.

Røpke, I. (2009) 'Theories of practice - new inspiration for ecological economic studies on consumption', Ecological Economics, Vol. 68, No. 10, pp.2490-2497.

Ruttonsha, P.L.Z. (2017) 'The many faces of design', FormAkademisk - Research Journal of Design and Design Education, Vol. 10, No. 1, https://doi.org/10.7577/formakademisk.1458 (Accessed 10 November, 2020).

Safarzyńska, K., Frenken, K. and Van Den Bergh, J.C.J.M. (2012) 'Evolutionary theorizing and modeling of sustainability transitions', Research Policy, Vol. 41, No. 6, pp.1011-1024.

Schäpke, N., Omann, I., Wittmayer, J.M., van Steenbergen, F. and Mock, M. (2017) 'Linking transitions to sustainability: a study of the societal effects of transition management', Sustainability, Vol. 9, No. 5: 737, doi: 10.3390/su9050737. 
Schatzki, T.R. (2001) 'Introduction: Practice theory', in Schatzki, T.R., Knorr Cetina, K. and von Savingy, E. (Eds.): The Practice Turn in Contemporary Theory, Routledge, London, New York, pp.1-14.

Schatzki, T.R. (2015) 'Practices, governance and sustainability', in Strengers, Y. and Maller, C. (Eds.): Social Practices, Intervention and Sustainability: Beyond Behaviour Change, Routledge, Oxfordshire, New York, pp.15-30.

Schön, D.A. (1983) The Reflective Practitioner: How Professionals Think in Action, Basic Books, New York.

Sengers, F., Wieczorek, A.J. and Raven, R. (2019) 'Experimenting for sustainability transitions: a systematic literature review', Technological Forecasting and Social Change, Vol. 145, pp.153-164.

Shove, E. (2003) Comfort, Cleanliness and Convenience: The Social Organisation of Normality, Berg, Oxford, New York.

Shove, E. and Trentmann, F. (Eds.) (2019) Infrastructures in Practice: The Dynamics of Demand on Networked Societies, Routledge, Abingdon, Oxon, New York, NY.

Shove, E. and Walker, G. (2007) 'CAUTION! transitions ahead: politics, practice, and sustainable transition management', Environment and Planning A: Economy and Space, Vol. 39, No. 4, pp.763-770.

Shove, E., Pantzar, M. and Watson, M. (2012) The Dynamics of Social Practice: Everyday Life and How It Changes, Sage, Los Angeles, CA.

Shove, E., Watson, M., Hand, M. and Ingram, J. (2007) The Design of Everyday Life, Oxford, Berg.

Smith, A. and Raven, R. (2012) 'What is protective space? Reconsidering niches in transitions to sustainability', Research Policy, Vol. 41, No. 6, pp.1025-1036.

Smith, A., Stirling, A. and Berkhout, F. (2005) 'The governance of sustainable socio-technical transitions', Research Policy, Vol. 34, No. 10, pp.1491-1510.

Smith, A., Voß, J.P. and Grin, J. (2010) 'Innovation studies and sustainability transitions: the allure of the multi-level perspective and its challenges', Research Policy, Vol. 39, No. 4, pp.435-448.

Spangenberg, J.H., Fuad-Luke, A. and Blincoe, K. (2010) 'Design for sustainability (DfS): the interface of sustainable production and consumption', Journal of Cleaner Production, Vol. 18, No. 15, pp.1485-1493.

Spurling, N. and McMeekin, A. (2015) 'Interventions in practices: sustainable mobility policies in England', in Strengers, Y. and Maller, C. (Eds.): Social Practices, Intervention and Sustainability: Beyond Behaviour Change, Routledge, Oxfordshire, New York, pp.78-94.

Strengers, Y. (2011) 'Designing eco-feedback systems for everyday life', Proceedings of CHI 2011 - Conference on Human Factors in Computing Systems, 7-12 May, Vancouver, B.C., pp.2135-2144, doi: 10.1145/1978942.1979252.

Strengers, Y. and Maller, C (Eds.) (2015) Social Practices, Intervention and Sustainability: Beyond Behaviour Change, Routledge, Oxfordshire, New York.

Torrens, J., Schot, J., Raven, R. and Johnstone, P. (2019) 'Seedbeds, harbours, and battlegrounds: on the origins of favourable environments for urban experimentation with sustainability', Environmental Innovation and Societal Transitions, Vol. 31, June, pp.211-232.

Turnheim, B., Berkhout, F., Geels, F., Hof, A., McMeekin, A., Nykvist, B. and van Vuuren, D. (2015) 'Evaluating sustainability transitions pathways: bridging analytical approaches to address governance challenges', Global Environmental Change, Vol. 35, pp.239-253.

Van den Bosch, S. and Rotmans, J. (2008) Deepening, Broadening and Scaling Up. A Framework for Steering Transition Experiments, Knowledge Centre for Sustainable System Innovations and Transitions (KCT), http://hdl.handle.net/1765/15812 (Accessed 10 November, 2020).

Veselova, E. and Gaziulusoy, A.I. (2019) 'Implications of the bioinclusive ethic on collaborative and participatory design', The Design Journal, Vol. 22, sup.1, pp.1571-1586. 
Vezzoli, C. and Manzini, E. (2008) 'Review: Design for sustainable consumption and production systems', in Tukker A., Charter, M., Vezzoli, C., Stø, E. and Andersen, M.M. (Eds.): System Innovation for Sustainability 1: Perspectives on Radical Changes to Sustainable Consumption and Production, Greenleaf, Sheffield, UK, pp.138-158.

Vezzoli, C., Ceschin, F. and Kemp, R. (2008) 'Designing transition paths for the diffusion of sustainable system innovations: a new potential role for design in transition management?', in Cipolla, C. and Peruccio, P.P. (Eds.): Proceedings of Changing the Change Conference: Design, Visions, Proposals and Tools, Umberto Allemandi, pp.440-454.

von Wirth, T., Fuenfschilling, L., Frantzeskaki, N. and Coenen, L. (2019) 'Impacts of urban living labs on sustainability transitions: mechanisms and strategies for systemic change through experimentation', European Planning Studies, Vol. 27, No. 2, pp.229-257.

Voss, J., Bauknecht, D. and Kemp, R (Eds.): (2006) Reflexive Governance for Sustainable Development, Edward Elgar, Cheltenham, UK, pp.103-130.

Waddell, S., Waddock, S., Cornell, S., Dentoni, D., McLachlan, M. and Meszoely, G. (2015) 'Large systems change', Journal of Corporate Citizenship, Vol. 58, pp.5-30.

Wals, A.E.J. and Rodela, R. (2014) 'Social learning towards sustainability: problematic, perspectives and promise', NJAS - Wageningen Journal of Life Sciences, Vol. 69, pp.1-3.

Weiland, S., Bleicher, A., Polzin, C., Rauschmayer, F. and Rode, J. (2017) 'The nature of experiments for sustainability transformations: a search for common ground', Journal of Cleaner Production, Vol. 169, pp.30-38.

Welch, D. and Yates, L. (2018) 'The practices of collective action: practice theory, sustainability transitions and social change', Journal for the Theory of Social Behaviour, Vol. 48, No. 3, pp.288-305.

Wittmayer, J. and Schäpke, N. (2014) 'Action, research and participation: roles of researchers in sustainability transitions', Sustainability Science, Vol. 9, No. 4, pp.483-496.

Young, R.A. (2008) 'An integrated model of designing to aid understanding of the complexity paradigm in design practice', Futures, Vol. 40, No. 6, pp.563-577.

Zolfgaharian, M., Walrave, B., Raven, R. and Romme, A.G.L. (2019) 'Studying transitions: past, present, and future', Research Policy, Vol. 48, No. 9: 103788, doi: 10.1016/j.respol. 2019.04.012. 